\title{
A Comparative Study of Pediatric Fracture Shaft Femur Fixating by Plate and Screws Using Lateral Approach Between Subvastus Lateralis and Transvastus Lateralis Outcome
}

\author{
Haider O. Hayat Ali Al-Faily ${ }^{1}$, Saif Nabeel Abd Alwahab² ${ }^{2}$ Mohammed Sh. Al-Edanni ${ }^{1 *}$ D , Sadeq A. Al-Mukhtar ${ }^{1}$, Ghadeer H. Majeed \\ ${ }^{1}$ Department of Orthopedic Surgery, Al-Kindy College of the Medicine, University of Baghdad, Baghdad, Iraq; ${ }^{2}$ Department of \\ Orthopedic Surgery, Ministry of Health, Baghdad, Iraq
}

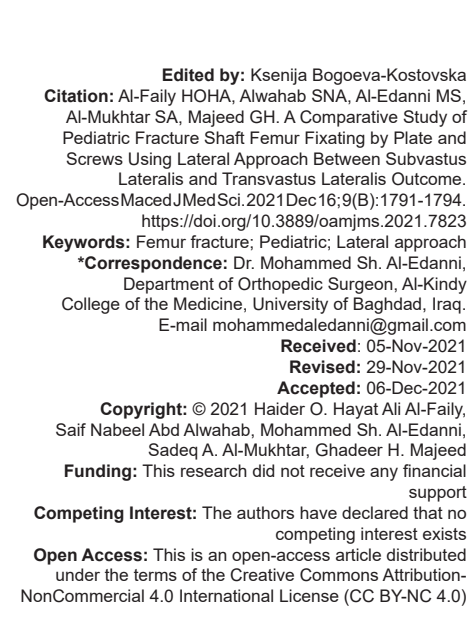

Introduction

Fractures shaft femur in pediatric age group occurs commonly in the middle diaphyseal region accounting for $62 \%$ of other femoral fractures in children. The incidence rate of femur shaft fracture is $19.5 / 100,000$ annually in children [1]. The goal of the management of such fracture is to achieve bone union with good alignment and restoration of the limb's function [2]. Many orthopedic surgeons manage this fracture conservatively with excellent remodeling of the immature bone in pediatric age group, on the other hand, other surgeons have revealed that shaft femur fractures in children do not always improve completely with non-surgical treatment [3]. Angulations, rotations, and shortenings not always adjusted by traditional treatment [4]. The conservative method, with reduction and early immobilization with a hip spica cast some time skin traction, is used before casting. This method may associate with some complications, such as loss of reduction and angulation or shortening of the limb [5], [6].
Four groups of blood vessels are responsible for nutrition of typical long bone, nutrient, metaphyseal, epiphyseal, and periosteal vessels. Usually, one nutrient entering the shaft of long bone through nutrient foremen, which is regarded as the chief source of blood to the long bones and thus is very vital in the development of bones during infancy, childhood, and all stages of bony ossification. This source represents about $70-80 \%$ of the blood supply of the bones, and ischemia of the bones can be result after restriction of this source [7], [8].

Modern techniques of plating shaft with minimal incisions, preservation of the periosteum, with long plates, and few select screw holes filling, have been accepted by several pediatric orthopedic trauma surgeons as an appreciated instrument to unstable femur fractures [9], [10].

Management of femoral fractures in 6-11 years old is extremely debated. For stable mild displaced femur fracture in children, immediate hip Spica casting is usually sufficient with good results, while older children with unstable and comminuted fractures, prefer a period 
of traction (skin traction) initially followed by cast brace or Spica cast [11]. Interest for management that reduce hospital stay allows to the external fixation and flexible intramedullary nails in children from 6 years old till maturity [4]. Compression plating has been reestablished as a method with little hazards and significant advantage in the treatment of pediatric femoral shaft fractures [4], [12].

Our aim of this study is to compare functional outcome fixation of midshaft of femur fracture in children by plate and screws between (subvastus lateralis and transvastus lateralis) regarding infection, union, and limitation of knee joint movement.

\section{Patients and Methods}

A prospective study consisted of 30 children who had femur fractures and were attending Al-Kindy Teaching Hospital in Baghdad from April 2018 till April 2020, 6 months' follow-up period.

The consent of the parents of the children was taken to be members of the current study. The study was divided into two samples; Group A treated by fixating shaft of the femur by plate and screw using subvastus lateralis approach and second sample; Group B fixating shaft of the femur by plate and screws using transvastus lateralis approach.

Our inclusion criteria are children between 3 and 10 years, butterfly midshaft femoral fractures, comminuted midshaft femoral fractures, oblique midshaft femoral fractures, and transverse midshaft femoral fractures, while children age under 3 years, children above 10 years, open fractures of the femur, proximal femoral fractures, distal femoral fractures, vascular injury, and pathological fractures were exclusive from the study.

Under general anesthesia, the child was put in supine position. A longitudinal lateral skin incision was made, tensor fascia lata was cut for both groups (Figure 1), then the bone exposed either a reflection vastus laterals muscle in Group A or through vastus laterals muscle in Group B. After the fracture site was

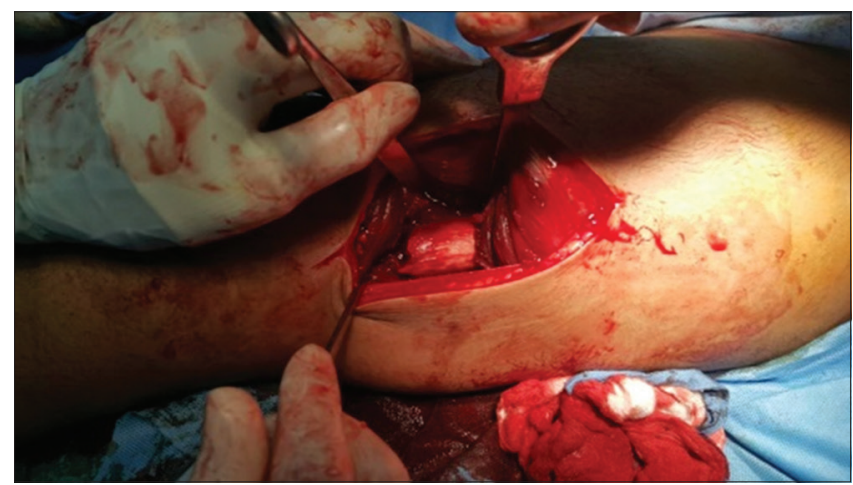

Figure 1: Intraoperative picture showing reflection of vastus lateralis muscle exposed, both bone ends are held with bone holders and the fracture reduce, then the bone fixating with plate (LCP type) and cortical screws $3.5 \mathrm{~mm}$ according to fracture pattern at least three screws proximal and three screws distal to fracture site (Figure 2a). Irrigation of wound done by normal saline and closed drain put in the wound, then suture the vastus laterals muscle in Group B and tensor fascia late and subcutaneous tissue in both groups and finally suture the skin and dressing done.

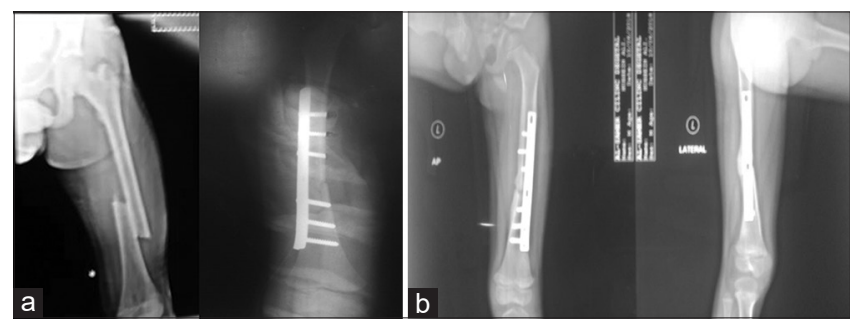

Figure 2: (a) Pre-and post-operative. (b) Three months'post-operative

Postoperatively, the child nursed supine without casting with a pillow under the affected limb while weight-bearing and limb motion was adapted according to the fracture shape and stability, the size of the implant, and associated injures. Partial weightbearing was permitted about the 4 weeks post-operative for the transverse types, while oblique and comminuted types were recommended to restrict weight-bearing on the fractured femur till early callus was observed on follow-up X-ray.

The patients were seen after 2 weeks, 4 weeks, 6 weeks, 3 months, and 6 months postoperatively (Figure $2 \mathrm{~b}$ ) and evaluated the functional recovery time regarding pain during movements in the knee joint, fracture healing time, range of movement of the knee joint, and specific complication.

The data were collected and analyzed using Statistical Package for the Social Sciences version 24. Descriptive statistics were represented as frequencies and proportions $(\%)$ or mean \pm SD. $P<0.05$ was considered statistically significant.

\section{Results}

In our study, there were four transversals, six obliques, and five comminuted fractures operated by subvastus approach (Group A), and five transversals, three oblique, and seven comminuted fractures operated by transvastus lateralis approach (Group B).

The average age was 3-10 years, there were no significant differences in the average ages, and the injuries were different causes, mostly due to trauma suffered by children, there were 17 injuries in the right thigh and 13 injuries in the left (Table 1).

The average union of the two groups, in subvastus group (Group A) occurs in all patients while 


\section{Table 1: Sample of study}

\begin{tabular}{llll}
\hline Data & No. & Group A & Group B \\
\hline $\begin{array}{l}\text { Number } \\
\text { Age }\end{array}$ & 30 & 15 & 15 \\
Sex & $3-10$ years & & \\
$\quad$ Male & & 8 & 12 \\
$\quad$ Female & 20 & 7 & 3 \\
Injured side & 10 & 9 & 8 \\
$\quad$ Right & & 6 & 7 \\
Left & 17 & & \\
\hline
\end{tabular}

in transvastus group (Group B) occurs in 14 cases out of 15 patients in 15 weeks, while one case of infection reported in Group B and none infection recorded in Group A.

Table 2 shows that $96.7 \%$ of the sample members of the study had a shaft union happen and $3.3 \%$ had non-union in Group B, while union in Group A was $100 \%$.

Table 2: Percentage of users of shaft union and infection

\begin{tabular}{lllll}
\hline Data & Subvastus & Transvastus & Sum & $\%$ \\
\hline Shaft union & 15 & 14 & 29 & 96.7 \\
Infection & 0 & 1 & 1 & 3.3 \\
Total & 15 & 15 & 30 & 100 \\
\hline
\end{tabular}

To identify the differences between the two groups that happened to have the shaft union and infection rate, the differences between the two groups were calculated.

The results in the Table 3 showed that after the completion of all process procedures, the infection rate is lesser and the union rate is higher in subvastus group than in transvastus group.

Follow-up of 30 patients shows that five patients had restriction of movement of knee joint in Group B and only two patients had restriction of the movement of knee joint in Group A, during 3 months of follow-up restriction of the movement of knee joint in Group B became one, while all patients retain normal knee joint movement in Group $A$ [Table 4]

\section{Discussion}

The outcome of our study was that infection occur in one case $(7 \%)$ and delay union also in one case $(7 \%)$ in transvastus group. This result agrees with Collin May [13] that had a rate of infection $6.8 \%$ and delays union $6.4 \%$ in splitting vastus lateralis. The union rate was $100 \%$ in subvastus group and this is similar to the results of other researchers, Reeves et al, Ward et al, Kregor et al and Van Niekerk [12], [14], [15], [16]. The infection rate in our study in subvastus group was $0 \%$ and the result agree with Reeves et al, Ward et al, Kregor et al and Van Niekerk [12], [14], [15], [16]. The limitation of knee movement in our study occurred in five patients out of 15 in transvastus group in first month postoperative(33.3\%) and became in one patient in three months postoperative $(6.66 \%)$ and at
Table 3: Differences between children in shaft union

\begin{tabular}{lllll}
\hline Data & Group A & p-value & Group B & p-value \\
\hline Shaft union & $\mathrm{n}(15)$ & 0.031 & $\mathrm{~N}(14)$ & 0.07 \\
Infection & 0 & 0.3 & 1 & $0(0.033)$ \\
Mean & 1.07 & & 1.0 & \\
STD & 0.258 & & 0.000 & \\
\hline
\end{tabular}

six months of follow up remain one patient $(6.66 \%)$. We agree with Riemer et al [17] who showed that limitation of knee movement was at 6 months in $7 \%$, while we no recorded any limitation of knee movement postoperative in our study in subvastus group follow up and this similar to result of Riemer et al [17].

Riemer et al. [16] who showed that the limitation of knee movement was at 6 months $7 \%$, and in our study, limitation of knee movement post-operative in subvastus group was $0 \%$ in the $3^{\text {rd }}$ month of follow-up and that agree with Riemer et al.

Table 4: Different rate of limitation of knee movement after operation

\begin{tabular}{llll}
\hline Data & Subvastus group & Transvastus group & Sum \\
\hline Limitation of knee movement $1^{\text {st }}$ month & $13.3 \%$ & $33.3 \%$ & $46.6 \%$ \\
Limitation of knee movement $3^{\text {rd }}$ month & $0 \%$ & $6.66 \%$ & $6.66 \%$ \\
\hline
\end{tabular}

\begin{tabular}{llll} 
Limitation of knee movement $3^{\text {rd }}$ month & $0 \%$ & $6.66 \%$ & $6.66 \%$ \\
\hline
\end{tabular}

We recommended to use the subvastus method in fixating shaft of femur in children by plate and screws, and long-term follow-up for those patients.

\section{Conclusions}

- $\quad$ Approved that in lateral approach in fixation midshaft femur in children, the subvastus lateralis results better than transvastus lateralis in the union of fracture and less rate of infection than transvastus lateralis

Limitation of knee movement occurs at a higher rate in transvastus lateralis than subvastus lateralis method.

\section{References}

1. Hinton RY, Lincoln $A$, Crockett $M M$, Sponseller $P$, Smith G. Fractures of the femoral shaft in children Incidence, mechanical, and sociodemographic risk factors. J Bone Joint Surg Am. 1999;81(4):500-9. https://doi. org/10.2106/00004623-199904000-00007

PMid:10225795

2. Flynn JM, Skaggs DL, Sponseller PD, Ganley TJ, Kay RM, Leitch $\mathrm{KK}$, et al. The operative management of pediatric fractures of the lower extremity. J Bone Joint Surg (Am). 2002;84:2288-300

PMid:12690889

3. Singh R, Sharma SC, Magu NK, Singla A. Titanium elastic nailing in pediatric femoral diaphyseal fractures. Ind $\mathrm{J}$ Ortho. 2006;40(1):29-34. 
4. Heinrich SD, Drvaric DM, Darr K, MacEwen GD. The operative stabilization of pediatric diaphyseal femur fractures with a flexible intramedullary nail: A prospective analysis. J Pediatr Orthop. 1994;14(4):501-7. https://doi. org/10.1097/01241398-199407000-00016

\section{PMid:8077436}

5. McCrory P. Campbell's Operative Orthopedics. $10^{\text {th }}$ ed., Vol. 4 British Journal of Sports Medicine;London; 2004.

6. Mansour AA $3^{\text {rd }}$, Wilmoth JC, Mansour AS, Lovejoy SA, Mencio GA, Martus JE. Immediate spica casting of pediatric femoral fractures in the operating room versus the emergency department: Comparison of reduction, complications, and hospital charges. J Pediatr Orthop. 2010;30(8):813-7. https:// doi.org/10.1097/BPO.0b013e3181fcb613

PMid:21102206

7. Poornima B and Angadi A V: A study of nutrient foramina of the dry adult human femur bones. International Journal of Biomedical Research 2015; 6(06): 370-373.

8. Longia GS, Ajmani ML, Saxena SK, Thomas RJ. Study of diaphyseal nutrient foramina in human long bones. Acta Anat (Basel). 1980;107(4):399-406. https://doi.org/10.1159/000145267 PMid:7405528

9. Caird MS, Mueller KA, Puryear A, Farley FA. Compression plating of pediatric femoral shaft fractures. J Pediatr Orthop. 2003;23(4):448-52.

PMid:12826941

10. Eren OT, Kucukkaya M, Kockesen C. Open reduction and plate fixation of femoral shaft fractures in children aged 4 to 10. J Pediatr Orthop. 2003;23(2):190-3. PMid:12604949

11. Stans AA, Morrissy RT, Renwick SE. Femoral shaft fracture treatment in patients ages 6 to 16 years.
J Pediatr Orthop. 1999;19(2):222-8. https://doi. org/10.1097/00004694-199903000-00017

PMid:10088693

12. Reeves RB, Ballard RI, Hughes JL. Internal fixation versus traction and casting of adolescent femoral shaft fracture. J Pediatr Orthop. 1990;1910(5):592-5. https://doi. org/10.1097/01241398-199009000-00004

PMid:2394812

13. May C, Yen YM, Nasreddine AY, Hedequist D, Hresko MT, Heyworth BE. Complications of plate fixation of femoral shaft fractures in children and adolescents. J Child Orthop. 2013;7(3):235-43. https://doi.org/10.1007/ s11832-013-0496-5

PMid:24432082

14. Ward WT, Levy J, Kaye A. Compression plating for child and adolescent femur fractures. J Pediatr Orthop. 1992;12(5):626-32.

PMid:1517424

15. Kregor PJ, Song KM, Routt MI Jr. Plate fixation of femoral shaft fractures in multiply injured children. J Bone Joint Surg Am. 1993;75(12):1774-80. https://doi. org/10.2106/00004623-199312000-00006

PMid:8258547

16. Van Niekerk JL, Dooren DP, Klasen HJ, Binnendijk B. Indications and results of osteosynthesis by plate fixation of femoral shaft fractures in children. Neth $J$ Surg. 1987;39(4):129-31. PMid:3683942

17. Riemer BL, Foglesong ME, Miranda MA. Femoral plating. Ortho Clin North Am. 1994;25(4):625-33.

PMid:8090475 